\title{
Regional cortical volumes and congenital heart disease: a MRI study in 22q11.2 deletion syndrome
}

\author{
Marie Schaer • Bronwyn Glaser • Marie-Christine Ottet • Maude Schneider • \\ Meritxell Bach Cuadra · Martin Debbané · Jean-Philippe Thiran · Stephan Eliez
}

Received: 9 February 2010 / Accepted: 23 August 2010 / Published online: 14 September 2010

(C) The Author(s) 2010. This article is published with open access at Springerlink.com

\begin{abstract}
Children with congenital heart disease (CHD) who survive surgery often present impaired neurodevelopment and qualitative brain anomalies. However, the impact of CHD on total or regional brain volumes only received little attention. We address this question in a sample of patients with 22q11.2 deletion syndrome (22q11DS), a neurogenetic condition frequently associated with CHD. Sixty-one children, adolescents, and young adults with confirmed 22q11.2 deletion were included, as well as 80 healthy participants matched for age and gender. Subsequent subdivision of the patients group according to CHD yielded a subgroup of 27
\end{abstract}

\author{
M. Schaer $(\bowtie) \cdot$ B. Glaser · M.-C. Ottet . \\ M. Schneider · M. Debbané · S. Eliez \\ Service Médico-Pédagogique, 1 rue David Dufour, \\ Case Postale 50, 1211 Geneva 8, Switzerland \\ e-mail: marie.schaer@unige.ch \\ B. Glaser \\ e-mail: bronwyn.glaser@unige.ch \\ M.-C. Ottet \\ e-mail: marie-christine.ottet@unige.ch \\ M. Schneider \\ e-mail: maude.schneider@unige.ch \\ M. Debbané \\ e-mail: martin.debbane@unige.ch \\ S. Eliez \\ e-mail: stephan.eliez@unige.ch \\ M. Bach Cuadra $\cdot$ J.-P. Thiran \\ Swiss Federal Institute of Technology, \\ Lausanne, Switzerland \\ M. Bach Cuadra \\ e-mail: meritxell.bach@epfl.ch \\ J.-P. Thiran \\ e-mail: jp.thiran@epfl.ch
}

patients with normal cardiac status and a subgroup of 26 patients who underwent cardiac surgery during their first years of life (eight patients with unclear status were excluded). Regional cortical volumes were extracted using an automated method and the association between regional cortical volumes, and CHD was examined within a three-condition fixed factor. Robust protection against type I error used Bonferroni correction. Smaller total cerebral volumes were observed in patients with CHD compared to both patients without CHD and controls. The pattern of bilateral regional reductions associated with CHD encompassed the superior parietal region, the precuneus, the fusiform gyrus, and the anterior cingulate cortex. Within patients, a significant reduction in the left parahippocampal, the right middle temporal, and the left superior frontal gyri was associated with CHD. The present results of global and regional volumetric reductions suggest a role for disturbed hemodynamic in the pathophysiology of brain alterations in patients with neurodevelopmental disease and cardiac malformations.

Keywords Velocardiofacial • Cardiac surgery • Neuroimaging $\cdot$ FreeSurfer

\section{Introduction}

Congenital heart diseases (CHD) are among the most frequent birth defects. Over the past few decades, progress in surgical techniques has allowed for the correction of most CHD, so that an increasing number of children and adults live with surgically corrected CHD (Wernovsky et al. 2005). Nevertheless, CHD and its correction still have neurological and developmental 
costs (Wray 2006). Survivors often present difficulties in expressive language, visuomotor skills, and fine motor function (Bellinger et al. 1999), as well as inattention and hyperactivity (Shillingford et al. 2008). Non-specific structural brain anomalies associated with these impairments have been reported, which include microcephaly, abnormalities of the cortical mantle (Glauser et al. 1990), and frequent periventricular leukomalacia (Gaynor 2004). The pathophysiology of brain anomalies associated with CHD has largely incriminated intraoperative support mechanisms, leading to continuous improvement of surgical procedures (Nelson et al. 2008). But more recently, it has also been evidenced that neurological abnormalities, such as microcephaly or leukomalacia, may be present before surgery (Limperopoulos et al. 1999; Mahle et al. 2002; Miller et al. 2007). As reduced cerebral blood flow has been shown in fetuses (Donofrio et al. 2003) and neonates with complex CHD (Licht et al. 2004), presurgical brain abnormalities may be the consequence of decreased perfusion pressure in the developing brain. Despite increasing evidence that reduced blood perfusion impairs brain growth in individuals with CHD, the quantification of cerebral volumes in children or adult survivors only received little attention. Further, the question as to how cerebral volume may be altered regionally in survivors remained similarly unaddressed.

If we look at brain anomalies related to CHD from another point of view, we cannot ignore the numerous neurogenetic conditions frequently associated with CHD in which abnormalities of the brain structure are well documented, such as Williams syndrome, Down syndrome, or 22q11.2 deletion syndrome (22q11DS; Meyer-Lindenberg et al. 2006; Schaer and Eliez 2007; Teipel and Hampel 2006; Gothelf et al. 2008; Martens et al. 2008). Among neurogenetic syndromes, the one with the strongest association with CHD is probably 22q11DS. Prospective studies of neonates with CHD have shown that deletion at 22q11.2 accounts for one third of patients with conotruncal heart defect (most often tetralogy of Fallot and truncus arteriosus) and one half of patients with interrupted aortic arch (Hay 2007). Moreover, $50 \%$ to $75 \%$ of patients with 22 q11DS have CHD (McDonald-McGinn et al. 1999; Ryan et al. 1997). In addition, to a strong bidirectional association between CHD and 22q11DS, striking similarities in the difficulties presented by children affected with 22q11DS and children with CHD have led to the suggestion that part of the cognitive or cerebral phenotype in 22q11DS may be caused by CHD (Wernovsky et al. 2005). Specifically, children with 22q11DS show visuospatial impairments, fine motor difficulties, executive dysfunction, and frequent attention problems (Gerdes et al. 1999; Swillen et al. 1999), all of which are commonly seen in non-syndromic patients with CHD. Although patients with 22q11DS and CHD demonstrate more severe intellectual impairments than patients with CHD alone (Atallah et al. 2007), comparing children with 22q11DS but with and without CHD offers an interesting framework to study the effect of CHD on brain structure and cognition. To date, no study has observed any differences in the cognitive outcome of children with 22q11DS with and without CHD (Gerdes et al. 1999; Simon et al. 2002; Bearden et al. 2001; Swillen et al. 1997; De Smedt et al. 2007). Similarly, previous neuroimaging studies grouping participants with widely varying CHD did not evidence any significant difference in brain morphology (Bearden et al. 2007; Bingham et al. 1997; Kates et al. 2001). However, using cardiac surgery as a strict clinical criteria, we previously observed a significantly reduced degree of cortical folding associated with CHD in patients with 22q11DS (Schaer et al. 2009), which suggests that the most severe cardiac anomalies affect early brain development in 22q11DS. In the present study, we address the question of regional volumetric reductions associated with CHD using a recent method that measure gyral volumes across the brain (Desikan et al. 2006). First, we quantify volumetric reductions that are specific to the syndrome by comparing patients to controls. Then, we identify the regions that are specifically altered in patients with surgically corrected CHD compared to patients without CHD.

\section{Materials and methods}

Participants

Individuals with $22 q 11 D S$

Sixty-one individuals with 22q11.2 deletion syndrome participated in the current study. The sample consisted of children, adolescents, and young adults, with an average age of $15.6 \pm 8.9$ (36 females, 25 males). Patients had an average IQ of $68.7 \pm 12.0$. Participants were recruited through announcements to regional parent associations. All individuals were native Frenchor English-speaking individuals and were assessed in their native language. Only children with a confirmed 22q11.2 deletion were included in the study. Aside from the large prevalence of cardiac malformations presented below, the 61 patients also presented a variety of medical comorbidities known to be commonly associated with the syndrome. Facial dysmorphic features and palate or pharyngeal malformations were highly 
prevalent (including 25 patients requiring corrective surgery); a large proportion of patients suffered from endocrine disorders including hypoparathyroidism or repeated infections due to thymic hypoplasia; three patients had unilateral renal agenesis. At the psychiatric level, 19 of the 61 patients presented hallucinations (nine females/ten males, average age $22.5 \pm$ 7.5), 17 delusions (eight females/nine males, average age $22.0 \pm 9.4$ ), and five met the DSM-IV criteria for schizophrenia (two females/three males, average age $31.2 \pm 4.5$ ). At the time of their participation, eight patients were taking psychotropic medications (four females/four males, average age $27.7 \pm 8.2$ ) and three were taking antiepileptic medications (two females/one male, average age $23.1 \pm 11.3$ ).

\section{Cardiac malformations in 22q11DS}

A history of cardiac surgery was documented using a questionnaire to the parents. In addition, medical reports, including ultrasound examinations and surgical reports, were examined. Twenty-seven patients with major cardiac defects were identified and constituted the CHD subgroup (17 females/ten males, mean age $13.7 \pm 8.3$ ). The type of CHD and the age at cardiac surgery are detailed for each patient in Table 1. Eight patients were excluded at analysis for unclear cardiac status (two with retroesophageal subclavian artery, six with documented interventricular communication with spontaneous closure at follow-up). Twenty-six patients with normal heart, or with benign heart murmurs at birth with normal ultrasound examination, were included in the noCHD subgroup (13 females/13 males, mean age $17.6 \pm 9.8)$. Although the age difference between the CHD and noCHD subgroups did not reach significance $(p=0.121)$, age was covaried out in all statistical analyses.

IQ scores in the subgroup of patients with CHD $(66.7 \pm 12.6)$ did not differ from IQ in the subgroup without $(70.0 \pm 11.6, p=0.333)$, neither did PIQ ( $p=$ $0.365)$ nor VIQ $(p=0.364)$. In further exploratory statistics, we subdivided all patients who we included in the CHD analyses $(n=53)$ into two subgroups of equal size according to their IQ performances. The low performing subgroup (FSIQ $\leq 67$ ) was composed of 26 patients with an average IQ of $58.2 \pm 6.7$ (mean age $17.3 \pm 9.5$ ), and the high performing subgroup (FSIQ $\geq$ 68) was composed of 27 patients with an average IQ of $78.1 \pm 7.0$ (mean age $14.1 \pm 8.8$ ). The proportion of low-performing patients in the CHD subgroup (17 out of $27,65.4 \%$ ) was significantly higher than the proportion of low-performing patients in the no-CHD subgroup (nine out of $26,34.6 \%, p=0.039, \phi=0.283$ ).
Table 1 Description of the subgroups with 22q11DS according to a history of major congenital cardiac malformation and subsequent surgery

\begin{tabular}{llll}
\hline Age & Sex & CHD & Age at cardiac surgery \\
\hline 6.1 & F & ASD, VSD & 3 months \\
6.1 & M & PHT, VSD & 3 months \\
6.3 & F & PAH, VSD & Surgery planned \\
6.3 & M & IAA, ASD, VSD & 1 and 3 months \\
6.4 & M & ToF & 5 months \\
7.0 & F & IAA, VSD & 1 month \\
7.3 & F & TA, VSD & 1 month \\
7.6 & M & PA-VSD (ToF) & 11 days \\
7.6 & F & ASD, VSD & 6 months \\
7.9 & F & ToF & 15 months \\
8.0 & F & PA-VSD (ToF) & 2 months and 3.5 years \\
8.6 & F & ASD, VSD & 5 months \\
10.9 & F & ASD, VSD & 8 months \\
11.2 & F & IAA, VSD & 8 days \\
11.9 & M & IAA, VSD & 9 days and 4 years \\
12.5 & M & ToF & 3 years \\
13.3 & M & ToF & 2.5 years \\
14.3 & F & ToF & 2 years \\
14.6 & F & ToF & 1 year \\
17.7 & F & Unspecified & 4 and 14 years \\
18.1 & M & IAA, VSD & At birth and 1 year \\
19.6 & F & IAA, VSD & 4 days and 3 months \\
21.6 & M & ToF & 17 months \\
23.3 & M & Aortic dysplasia & During 1st year \\
30.0 & F & ToF & 3 and 5 years \\
32.5 & F & ASD & During 1st year \\
33.4 & F & PAH, VSD & 11 years \\
\hline & & &
\end{tabular}

$F$ female, $M$ male, $T o F$ tetralogy of fallot, $V S D$ ventricular septal defect, $A S D$ atrial septal defect, $I A A$ interrupted aortic arch, $P A H$ pulmonary artery hypoplasia, $P A-V S D$ pulmonary atresia with ventricular septal defect (often considered to be the most severe of the ToF defects), PHT pulmonary hypertension, TA truncus arteriosus

This difference appeared mainly driven by the adolescents and adults with CHD, as the nine patients with CHD who were older than 14 years old were all low performers.

Among the patients with hallucinations, the proportion of patients with CHD (six out of 27) did not significantly differ from the proportion of patients without (nine out of $26, p=0.372, \phi=-0.138$; four patients with hallucinations were not included in the cardiac analyses because of their unclear cardiac status). The proportion of patients with CHD and delusions (five out of 27) did not significantly differ from the proportion of patients with delusions and without CHD (11 out of $26, p=0.077, \phi=-0.259$; one patient with delusion and unclear cardiac status). Finally, the proportion of patients with schizophrenia and CHD (two out of 27) did not significantly differ from the proportion of patients with schizophrenia and without CHD (two out of $26, p=1.0, \phi=-0.005)$. 


\section{Control group}

The comparison group was comprised of 80 typically developing individuals ( 44 females, 36 males). The control group had an average age of $15.9 \pm 8.4$ and an average IQ of $111.7 \pm 12$. Individuals were recruited through a newsletter distributed at public schools and in the Geneva community. A complete medical history, as well as parent report (CBCL in children and adolescents; Achenbach 1991) and self-report (SCL-90R in adolescents and adults; Derogatis 1983) behavioral questionnaires were used to screen control participants. Subjects with a history of past or present neurological or psychiatric disorders were excluded. Written informed consent was received from all subjects, as well as the parents of subjects younger than 18 years of age, in accordance with protocols approved by the Institutional Review Board of Geneva University School of Medicine.

\section{MRI acquisition and processing}

Cerebral magnetic resonance images were acquired with a T1-weighted 3D volumetric pulse sequence using a Philips Intera 1.5-T scanner as a series of 124 contiguous coronal slices, with a voxel size of $0.9375 \times$ $0.9375 \times 1.5 \mathrm{~mm}(\mathrm{TR}=35 \mathrm{~ms}, \mathrm{TE}=6 \mathrm{~ms}$, flip angle $=$ $\left.45^{\circ}, \mathrm{NEX}=1\right)$.

Cortical reconstruction and volumetric segmentation were performed using published algorithms included in FreeSurfer software (Harvard University; Dale et al. 1999; Fischl et al. 2001). Briefly, processing consisted of removal of non-brain tissue (Sgonne et al. 2004), automatic segmentation of the subcortical gray matter structures (Fischl et al. 2002), and the extraction of cortical surfaces, which was performed according to previously published protocols (Dale et al. 1999; Fischl and Dale 2000). Both intensity and continuity information from the entire three-dimensional MR volume are used in segmentation and deformation procedures, thus producing accurate representation of cortical thickness or volumes. These procedures have been validated against histological studies (Rosas et al. 2002), manual measurements (Kuperberg et al. 2003; Salat et al. 2004), and shown reliable across scanner manufacturers and field strengths (Han et al. 2006).

Subsequent to cortical reconstruction, the cortex is subdivided into units based on gyral and sulcal structures (Desikan et al. 2006). This parcellation method based on major sulci has been shown to be both valid and reliable, with high intraclass correlation coefficient between the manual and automated procedures for both cortical volume estimates and parcel boundaries.
The parcellation produces 34 gyral regions subdivided into 11 frontal regions, nine temporal regions, five parietal regions, four occipital regions, four parts of the cingulate cortex, and finally the corpus callosum which is designed to improve the reliability of the placement of the other parcels (for details, please refer to the validation article; Desikan et al. 2006). In the present study, the frontal pole and the banks of the superior temporal sulcus regions that exhibited relatively poor reliability in the validation article were excluded from statistical analyses. Cortical volume was therefore estimated for 31 parcels in each hemisphere for each subject.

\section{Statistical analyses}

\section{Patients vs controls}

ANOVA was used to compare total cerebral volume between groups. Subsequent MANCOVA compared the 31 ROIs in each hemisphere with diagnosis as the fixed factor and both age and total cerebral volume as covariates. Results are reported both with a statistical threshold of $p<0.05$ and with a Bonferroni's corrected threshold of $p<0.0016$.

\section{Patients with and without $C H D$}

In order to test whether volumetric alterations were associated with CHD, we then conducted the same MANCOVA on the 31 parcels in each hemisphere, using age and total cerebral volume, but with three conditions as our fixed factor (control, patient with CHD, patient without CHD). IQ was not included as a covariate in the model, as it was not a significant predictor of the model (left: $p=0.955$; right: $p=0.545$ ). Parcels that were significant at $p<0.05$ were further tested in pairs using a Scheffe post hoc on cortical volumes residualized for age. Post hoc results are also reported at $p<0.05$ and $p<0.0016$.

In order to assess the specificity of cardiac malformations or surgery against other type of malformations or surgery, we also compared total and regional cerebral volumes between the 25 patients who underwent palate or pharyngeal surgery (14 females/ 11 males, average age $17.0 \pm 9.6)$ and the 36 patients without ( 22 females/14 males, average age $14.7 \pm 8.4$ ). Of note, the presence of severe palate or pharyngeal malformations was not associated with the presence of CHD in our sample of patients (11 of the 16 patients without CHD and ten of the 27 patients with CHD underwent palate or pharyngeal surgery). 


\section{Results}

Patients vs controls

A $12.4 \%$ reduction in cerebral volume was observed in patients with 22 q11DS compared to controls (see Table 2), the regional distribution of which is further depicted in Fig. 1. Specifically, Fig. 1 demonstrated that cortical reductions seen in 22q11DS were the largest in the posterior and medial parts of the brain.

Detailed statistical significance reported in Table 2 confirms the pattern of cortical alteration visible in Fig. 1. Significantly preserved (i.e., relatively increased) cortical regions in the syndrome are exclusively located in the frontal lobes. Posterior regions with the greatest reduction in $22 q 11 D S$ reach almost equal significance in both hemispheres, at the precuneus, fusiform gyrus, and the most anterior part of the cingulate cortex. Widespread reductions are also observed in the parietal and occipital lobes, although these did not reach significance after correcting for the number of tests.

\section{Patients with and without CHD}

We observed a prominent association between congenital heart disease and reduced total and regional cerebral volumes. While patients with 22q11DS and normal cardiac status showed a $6.9 \%$ reduction in total cerebral volume compared to controls, patients who underwent cardiac surgery had an average of $16.9 \%$ reduction. Statistical significance in Table 3 demonstrates two patterns of cortical changes in patients with

Table 2 Regional cortical volumetric changes in patients with 22q11DS compared to controls

\begin{tabular}{|c|c|c|c|c|c|}
\hline & & Control & 22q11DS & $F$ & $p$ \\
\hline & Total cerebral volume ${ }^{a}$ & $1,072,287(101,804)$ & $939,831(114,254)$ & 52.7 & $<0.001$ \\
\hline \multicolumn{6}{|c|}{ Cortical regions showing relative preservation in 22q11DS } \\
\hline \multirow[t]{6}{*}{ Left } & Lateral orbitofrontal & $8,227.3(983.6)$ & $8,055.4(1,162.2)$ & 20.4 & $<\mathbf{0 . 0 0 1}$ \\
\hline & Pars opercularis & $5,176.7(925.3)$ & $5,242.4(984.8)$ & 6.0 & 0.016 \\
\hline & Precentral & $14,684.5(1,575.4)$ & $14,188.6(1,841.1)$ & 5.7 & 0.019 \\
\hline & Pars orbitalis & $2,743.0(456.8)$ & $2,628.7(591.3)$ & 5.7 & 0.019 \\
\hline & Superior frontal & $27,430.5(3,653.1)$ & $25,494.9(3,990.5)$ & 4.8 & 0.030 \\
\hline & Medial orbitofrontal & $5,106.4(880.8)$ & 4,955.8 (787.7) & 4.3 & 0.041 \\
\hline \multirow[t]{4}{*}{ Right } & Precentral & $14,493.0(1,806.5)$ & $14,117.5(2,006.4)$ & 15.0 & $<\mathbf{0 . 0 0 1}$ \\
\hline & Superior frontal & $25,605.5(3,313.5)$ & $24,819.5(3,713.7)$ & 13.5 & $<\mathbf{0 . 0 0 1}$ \\
\hline & Lateral orbitofrontal & $8,273.2(954.5)$ & 7,901.0 (1,381.6) & 12.2 & $<\mathbf{0 . 0 0 1}$ \\
\hline & Pars orbitalis & $3,196.3(630.0)$ & $3,097.5(659.3)$ & 5.3 & 0.023 \\
\hline \multicolumn{6}{|c|}{ Cortical regions showing disproportionate reductions in 22q11DS } \\
\hline \multirow[t]{8}{*}{ Left } & Precuneus & $11,187.8(1,633.8)$ & $9,164.4(1,705.3)$ & 23.3 & $<\mathbf{0 . 0 0 1}$ \\
\hline & Fusiform & $10,379.1(1,443.6)$ & $8,413.5(1,534.4)$ & 16.8 & $<\mathbf{0 . 0 0 1}$ \\
\hline & Rostral ant. cingulate & $2,701.1(600.7)$ & $2,025.7(471.3)$ & 12.7 & $<\mathbf{0 . 0 0 1}$ \\
\hline & Temporal pole & $2,672.6(500.4)$ & $2,278.3(419.0)$ & 11.4 & $<\mathbf{0 . 0 0 1}$ \\
\hline & Cuneus & $3,356.7(686.1)$ & $2,636.8(536.5)$ & 9.4 & 0.003 \\
\hline & Superior parietal & $14,728.9(2,562.2)$ & $12,750.4(2,058.1)$ & 7.3 & 0.008 \\
\hline & Caudal ant. cingulate & $2,031.5(583.1)$ & $1,567.9(315.5)$ & 6.8 & 0.010 \\
\hline & Pericalcarine & $2,258.7(514.7)$ & $1,754.0(426.1)$ & 4.2 & 0.041 \\
\hline \multirow[t]{11}{*}{ Right } & Precuneus & $11,452.6(1,967.0)$ & $9,418.3(1,472.7)$ & 19.6 & $<0.001$ \\
\hline & Lingual & $7,545.5(1,292.4)$ & $6,122.9(954.0)$ & 13.5 & $<0.001$ \\
\hline & Rostral ant. cingulate & $2,123.5(430.2)$ & $1,658.0(383.2)$ & 13.4 & $<0.001$ \\
\hline & Fusiform & $9,628.3(1,430.3)$ & $7,628.4(1,732.7)$ & 11.8 & $<\mathbf{0 . 0 0 1}$ \\
\hline & Cuneus & $3,860.5(791.1)$ & $3,118.3(672.2)$ & 5.8 & 0.017 \\
\hline & Rostral middle frontal & $20,440.6(3,307.4)$ & $17,679.1(2,576.0)$ & 4.9 & 0.028 \\
\hline & Temporal pole & $2,572.04(574.1)$ & $2,178.6(394.6)$ & 4.8 & 0.030 \\
\hline & Caudal ant. cingulate & 2,450.1 (679.0) & $1,943.9(434.3)$ & 4.8 & 0.030 \\
\hline & Lateral occipital & $14,206.3(2,243.5)$ & $12,217.8(1,992.1)$ & 4.8 & 0.031 \\
\hline & Superior parietal & $14,360.8(2,222.5)$ & $12,688.9(1,956.1)$ & 4.5 & 0.036 \\
\hline & Pericalcarine & $2,593.0(602.1)$ & 2,054.7 (417.9) & 4.0 & 0.049 \\
\hline
\end{tabular}

In both hemispheres, MANCOVA comparing regional brain volumes while covarying for age and total cerebral volume were significant at Wilks' lambda of $p<0.001$ (left: $F_{33,105}=4.808$; right: $F_{33,105}=3.538$ ). Cortical regions significant at the Bonferroni's corrected threshold of $p<0.0016$ are highlighted in bold. All cortical volumes are expressed in cubic millimeters

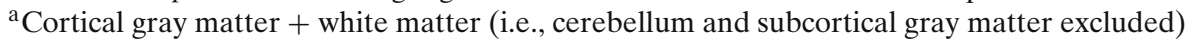


Fig. 1 Distribution of cortical reduction associated with 22q11DS plotted on the average study-specific brain. Percentage of volumetric reduction is illustrated using a scale centered at average cerebral reduction $(-12 \%$, green). Blue regions demonstrate relative preservation (i.e., less than $12 \%$ of reduction) and yellow to red regions indicate regions with the greatest percentage reduction

\section{Percentage of cortical reduction in 22q11.2DS}
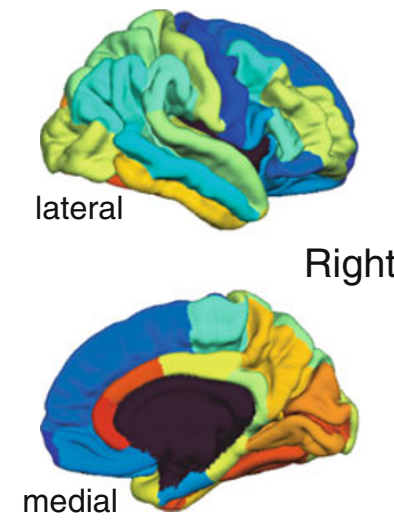
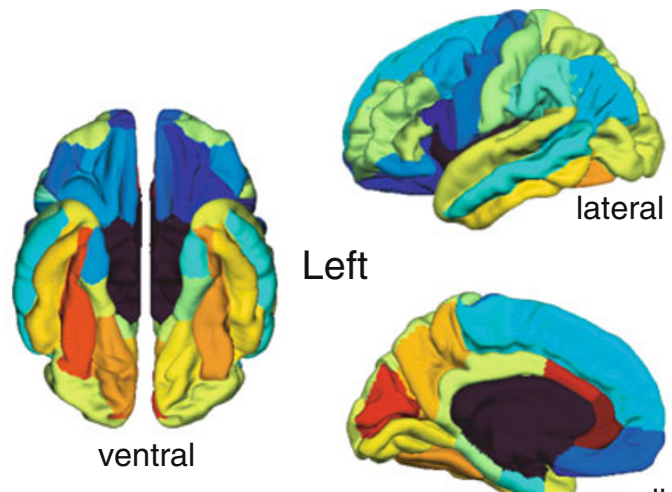

Left

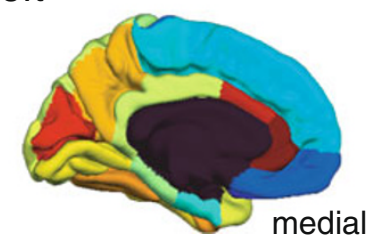

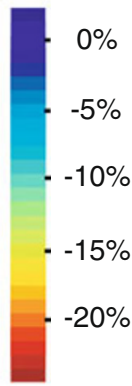

In further exploratory statistics, we conducted correlational analyses between age at cardiac surgery and cerebral volumes. Though, age at surgery was not a significant predictor of total cerebral volume, neither in the whole subgroup of patients with CHD (Pearson's correlation coefficient $=-0.014, p=0.944)$ nor after excluding the outlier patient who was operated at 11 years old (Pearson's correlation coefficient $=0.203$, $p=0.331)$. Similarly, no significant effect of age at surgery was observed on regional cortical volumes in

Table 3 Statistical significance of regional cortical volume differences in the three-groups comparison

\begin{tabular}{|c|c|c|c|c|c|c|}
\hline & & \multicolumn{2}{|c|}{ MANCOVA } & \multicolumn{3}{|c|}{ Post hoc (Scheffe test) } \\
\hline & & $F$ & $p$ & $\mathrm{Ctl}$ vs noCHD & $\mathrm{Ctl}$ vs $\mathrm{CHD}$ & noCHD vs CHD \\
\hline \multirow{10}{*}{ Left } & Cerebrum & 31.5 & $<0.001$ & 0.009 & $<0.001$ & 0.001 \\
\hline & Precuneus & 13.4 & $<0.001$ & $<0.001$ & $<0.001$ & 0.031 \\
\hline & Lateral orbitofrontal & 10.8 & $<0.001$ & 0.278 & 0.036 & 0.003 \\
\hline & Fusiform & 7.6 & 0.001 & $<0.001$ & $<0.001$ & 0.120 \\
\hline & Rostral ant. cingulate & 5.9 & 0.003 & $<0.001$ & $<0.001$ & 0.165 \\
\hline & Cuneus & 4.8 & 0.010 & 0.001 & $<0.001$ & 0.097 \\
\hline & Parahippocampal & 4.7 & 0.010 & 0.399 & $<0.001$ & 0.001 \\
\hline & Superior parietal & 3.9 & 0.022 & 0.010 & $<0.001$ & 0.037 \\
\hline & Superior frontal & 3.4 & 0.035 & 0.978 & $<0.001$ & 0.001 \\
\hline & Precentral & 3.3 & 0.041 & 0.075 & 0.037 & 0.077 \\
\hline \multirow[t]{9}{*}{ Right } & Precuneus & 10.3 & $<0.001$ & $<0.001$ & $<0.001$ & 0.012 \\
\hline & Precentral & 7.7 & 0.001 & 0.419 & 0.011 & 0.002 \\
\hline & Superior frontal & 6.5 & 0.002 & 0.720 & 0.008 & 0.006 \\
\hline & Rostral ant. cingulate & 6.5 & 0.002 & 0.001 & $<0.001$ & 0.033 \\
\hline & Lateral orbitofrontal & 6.4 & 0.002 & 0.994 & 0.013 & 0.046 \\
\hline & Fusiform & 6.2 & 0.003 & 0.002 & $<0.001$ & 0.001 \\
\hline & Lingual & 5.5 & 0.005 & 0.001 & $<0.001$ & 0.089 \\
\hline & Superior parietal & 3.1 & 0.049 & 0.030 & $<0.001$ & 0.012 \\
\hline & Middle temporal & 3.1 & 0.050 & 0.967 & $<0.001$ & 0.002 \\
\hline
\end{tabular}

Cortical regions that showed significant difference in the three-condition fixed-factor MANCOVA were further tested for differences $2 \times 2$ using a Scheffe test on the cortical volumes residualized for age. The whole MANCOVA was highly significant in both hemispheres (left: $F_{62,196}=2.803$; right: $\left.F_{62,196}=2.268\right)$. The most significant regions $(p<0.0016)$ are highlighted in bold and further illustrated in Fig. 2 
Differences in total and regional cerebral volumes related to $\mathrm{CHD}$

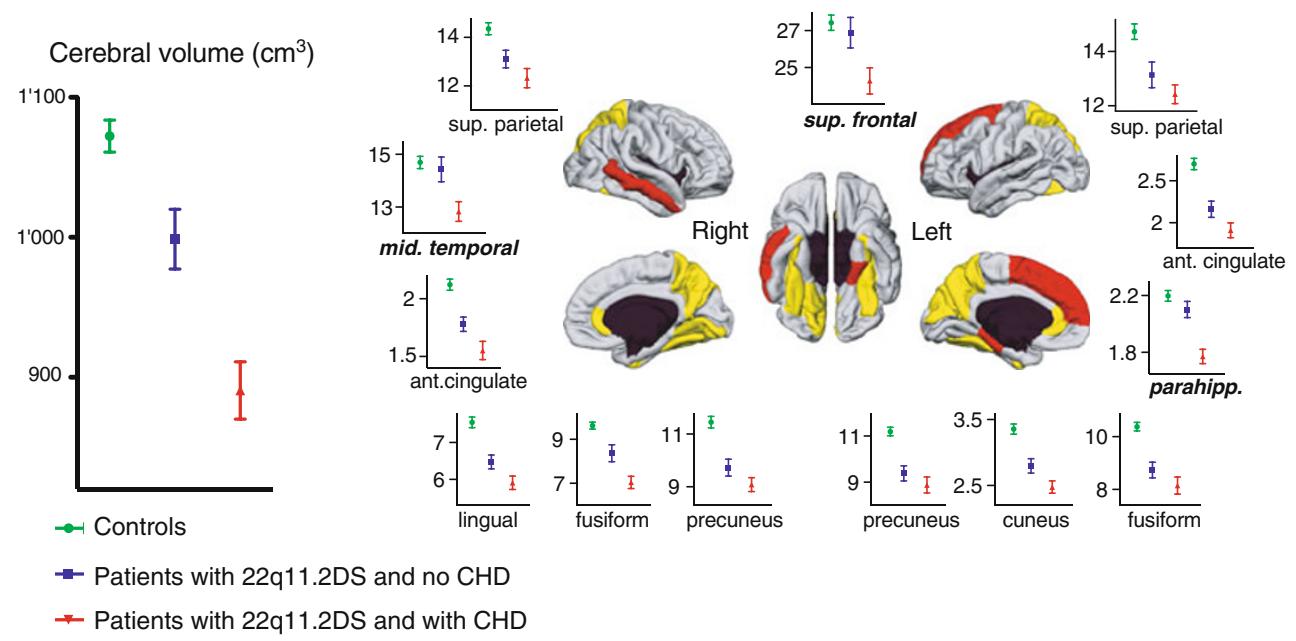

Fig. 2 Total and regional volumetric differences related to CHD. Patients with 22q11DS and CHD showed more drastic reductions in total brain volume than patients without CHD, compared to typically developing individuals. The regional distribution of the most significant parcels driving average cerebral reduction is also shown: yellow regions demonstrate areas where patients with normal cardiac status show intermediate reductions between normal controls and patients with $\mathrm{CHD}$; red depicts regions where reduction is exclusively related to the presence of CHD the 31 parcels (after excluding the outlier, right hemisphere: $p=0.792$, left hemisphere: $p=0.492$ ).

Finally, using palate or pharyngeal surgery as the fixed factor, we did not evidence any difference in total $(p=0.731)$ or regional cerebral volumes (right hemisphere: $p=0.771$, left hemisphere: $p=0.737)$.

\section{Discussion}

In the present study, we used an accurate method for measuring regional volumes over the cortex in 22q11DS with the specific aim of quantifying the effect of CHD on brain development in the syndrome. In the entire cohort of patients with 22q11DS, independent of their cardiac status, we were able to replicate previous volumetric results that used other methods (Eliez et al. 2000; Kates et al. 2001; Simon et al. 2005; Kates et al. 2004; Campbell et al. 2006). In summary, the $12.4 \%$ reduction of the cerebrum observed here is in accordance with previous measurements (Eliez et al. 2000; Kates et al. 2001). Further, thanks to the increased precision allowed by maps of continuous volumetric changes over the cortex, we were able to confirm the rostrocaudal gradient in brain alterations that has been previously suggested using techniques with poorer spatial resolution. Indeed, as noted by Gothelf et al. (2008), a more important reduction of caudal structures was evidenced at the lobar level (Eliez et al. 2000; Kates et al. 2001; Simon et al. 2005), as well as in specific regions of inter- ests such as basal ganglia (Kates et al. 2004; Campbell et al. 2006; Eliez et al. 2002), the thalamus (Bish et al. 2004), the corpus callosum (Machado et al. 2007), and the fusiform gyrus (Glaser et al. 2007). Turning to potential implications of the rostrocaudal gradient of brain alterations, several authors have pointed out that frontal preservation may help to protect verbal performances in children with 22q11DS, while posterior reduction may alter arithmetic and visuospatial skills (Eliez et al. 2000; Simon et al. 2005; Kates et al. 2004; Campbell et al. 2006).

In addition to a rostrocaudal gradient, the precision brought by the continuous measurement over the three-dimensional cortical surface also demonstrates a previously unreported lateromedial gradient of brain alterations in 22q11DS. As a result of the rostrocaudal and lateromedial gradients, we observe that the regional distribution of cortical reductions on Fig. 2 is proximal to the territory supplied by the posterior cerebral artery. The posterior cerebral artery supplies the brain stem, cerebellum, caudal part of the thalamus, and striatum and the uncus, fusiform gyrus, inferior temporal gyrus, pericalcarine region, cuneus, lingual gyrus, precuneus, and the occipital pole at the cortical level (see also Fig. 3, adapted from an article by van der Zwan and Hillen 1991). Given that various vascular anomalies are commonly associated with 22q11DS, Shprintzen (2000) has suggested that abnormal brain development in the syndrome may be caused by reduced perfusion related to cerebrovascular malformations. 

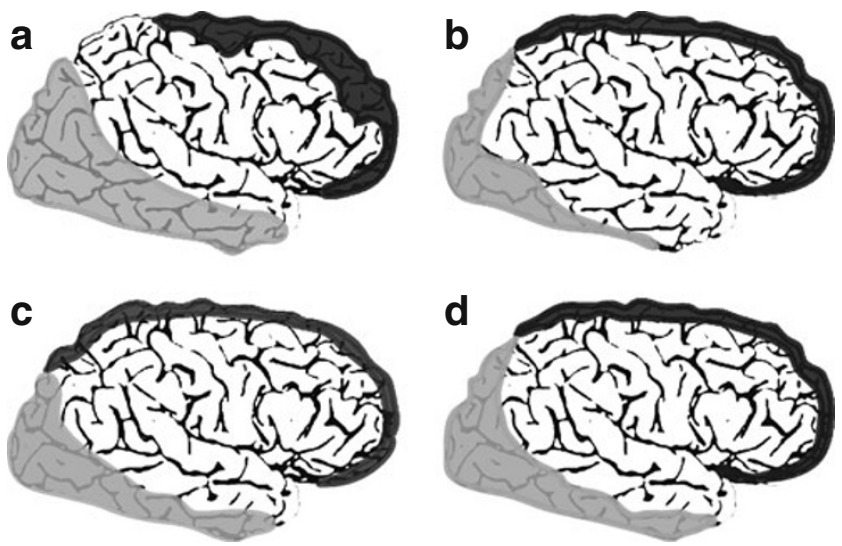

Fig. 3 Variability in the arterial territories (adapted from the article by van der Zwan and Hillen 1991). Territories supplied by the anterior (white), middle (black), and posterior (gray) cerebral are schematically reproduced, illustrating possible variations (from a to d)

However, we were missing empirical support for this hypothesis. Only one study reported cerebral angiography in the syndrome (Chow et al. 1999), observing up to $55 \%$ of minor vascular anomalies. Despite this angiographic study included a small number of subjects, Chow and colleagues reported an increased incidence of hypoplasia of the (right) posterior cerebral artery. Based on Shprintzen's original hypothesis and on the angiographic observations by Chow et al., we speculate that the cortical reductions observed here point to reduced blood flow in the territory of the posterior cerebral artery, possibly altering cerebral growth in these regions. The observation that non-cortical regions supplied by this artery are also reduced corroborates this hypothesis (namely the brain stem (Eliez et al. 2001), cerebellum (Eliez et al. 2001; Bish et al. 2006), caudal part of the thalamus (Bish et al. 2004), and caudal part of the corpus callosum (Machado et al. 2007; Antshel et al. 2005)). The potential implications of reduced blood supply over the territory of the posterior cerebral artery opens avenues for more detailed exploration of cerebrovascular anomalies in the syndrome.

A vascular hypothesis of cerebral alterations in the syndrome is even more likely given the regional distribution of reduced cortical volumes in the group of patients with CHD. Among regions exclusively affected in presence of congenital heart disease are the (left) superior frontal gyrus and the (right) middle temporal gyrus. Again, these differences may be analyzed in light of the arterial supply territories. As depicted in Fig. 3, variability in arterial territories is relatively high. However, the superior frontal and the middle temporal gyri are the only two gyri for which their entire length is located at the junction between two arterial territories (namely between the anterior and middle cerebral arteries for the middle frontal gyrus, and between the anterior and the posterior arteries for the middle temporal gyrus). Decades of neurological observations have taught us that these regions, known as watershed areas, are the first to suffer with reduced perfusion pressure in the brain (Liu et al. 2001; Chao et al. 2006). We can thus speculate that hypoperfusion related to CHD has particularly impaired brain growth in the superior frontal and middle temporal gyri.

Finally, we also observed a specific reduction of the left parahippocampal region associated with CHD. While a direct association between this region and arterial territories is less straightforward, this finding becomes interesting in light of the known vulnerability of this region to a variety of stressful events. Indeed, the hippocampus (a non-cortical region which was not measured in the present study, but which is known to be reduced in the syndrome: Debbané et al. 2006; Deboer et al. 2007; Kates et al. 2006) is a structure known to be highly sensitive to anoxia (Di Paola et al. 2008; Jourdain et al. 2002) or to diverse kind of stress (Bremner et al. 1995; McEwen 1999; Sapolsky 2000). It is possible that the nearby parahippocampal region is similarly sensitive to stress related to CHD or to surgery on the post-natal developing brain.

We argue that the absence of cerebral repercussions of the other core malformations associated with the syndrome, namely palate or pharyngeal malformations, as well as the above-mentioned reasons, both support a specific role for hemodynamic factors in reduced cortical volumes in patients with CHD. Though, alternative explanations also need to be considered. Indeed, the association between CHD and the observed cerebral anomalies may be a co-occurrence rather than a causative effect. Common embryologic origins of the malformed heart and brain could be incriminated. For instance, abnormal migration of cells of the neural crest is thought to be partially responsible for heart anomalies in 22q11DS (Scambler 2000) and may also be a good candidate for certain brain alterations.

The present study opens avenues for furthering our understanding of the pathophysiology of brain alterations in 22q11DS and related to CHD. However, the establishment of a clear relationship between hemodynamic status and the observed volumetric reductions remains impaired by some limitations. First, cardiac defects are largely incomparable in terms of hemodynamic disturbance, and unfortunately, the present sample size does not allow extensive explorations of the effect of specific cardiac malformations on brain structure. Second, information about cardiac status was ob- 
tained retrospectively from cardiologists, at the time of the patients evaluation in our research program. In the present sample, surgical procedures were performed in different hospitals in Switzerland or in France between 1971 and 1996. As a result, measures which would have been interesting to correlate with brain volumes, such as for instance oxymetry, were not available. Finally, due to the lack of angiographic data, we were not able to confirm a clear association between cerebrovascular malformations and cerebral reductions. Accordingly, recommendations for future studies in the syndrome include (1) a precise data collection about cardiac history in all patients with 22q11DS and (2), if possible, the acquisition of angiographic exams (e.g., magnetic resonance angiography) jointly with other structural MRI acquisitions.

Whatever the cause of the additional volumetric alterations in patients with CHD, the findings of the current study point to potential cognitive repercussions. For instance, we observed that a significantly larger proportion of low performing patients were found in the CHD than in the noCHD subgroups. We also observed that none of the adults with 22q11DS who underwent cardiac surgery were included in the high-performing subgroup of patients. If we expected stronger cognitive differences, there may be several explanations for the absence of a clearer association between performances and CHD in the present study. First, heterogeneity of CHD and surgical procedures in the CHD subgroup may explain a lack of clear differences in cognitive performances in patients with and without CHD. Indeed, different CHD (Limperopoulos et al. 1999), different surgeries (Bellinger et al. 1995), or different ages at surgery (Newburger et al. 1984) have all been identified as important determinants of cognitive outcome. Second, it is possible that the effect of CHD on cognitive outcome, as we are able to measure it, may remain subtle in this genetic syndrome which is already associated with a consequent mental delay (i.e., without CHD). Even if we identified specific volumetric alterations related to $\mathrm{CHD}$, these alterations may not be directly translated into isolated cognitive deficits. Similarly, Bellinger (2003) has discussed how pediatric cardiac surgery differs from adult surgery, pointing out that one occurs in a developmental and plastic setting, whereas the other is more likely to result in "static neuropsychological deficits". Finally, the lack of clear relationship between CHD and intelligence in the entire sample of patient contrasts the difference in cognitive performances observed between adults with and without CHD. As Bellinger (2003) suggested, some deficits may remain silent until the child learns more complex tasks or, more optimistically, the difference between children and adults' outcomes may rely on evolution in cardiac surgical procedures during the last decade.

\section{Conclusion}

In the present study, we propose that the distribution of reduced cortical volumes supports an impact of hemodynamic alterations both in 22q11DS and in CHD, opening avenues for exploring cerebrovascular malformations and their relationship with cognitive outcome in the syndrome. First, we evidenced a rostrocaudal and a lateromedial gradient of cortical reduction in 22q11DS, which may support a role for reduced blood supply in the territory supplied by the posterior cerebral artery. Second, this study is also the first to report changes to regional cortical volume related to CHD. Even if these changes occur within the wider context of the syndrome, we argue that they provide clues for furthering our understanding of the neurology of CHD and of the intellectual impairments often reported in children who underwent cardiac surgery.

Acknowledgements This research was supported by Swiss National Research Funds (grant 323500-111165 to M.S. and grants 3200-063135, 3232-063134, and PP00B-102864 to S.E.), by NARSAD Institute, and by the Center for Biomedical Imaging of the Geneva, Lausanne Universities and the EPFL, as well as the foundations Leenaards and Louis-Jeantet (www.cibm.ch).

Open Access This article is distributed under the terms of the Creative Commons Attribution Noncommercial License which permits any noncommercial use, distribution, and reproduction in any medium, provided the original author(s) and source are credited.

\section{References}

Achenbach T. Child behavior checklist/4-18. Burlington: University of Vermont, Department of Psychiatry; 1991.

Antshel KM, Conchelos J, Lanzetta G, Fremont W, Kates WR. Behavior and corpus callosum morphology relationships in velocardiofacial syndrome (22q11.2 deletion syndrome). Psychiatry Res. 2005;138:235-45.

Atallah J, Joffe AR, Robertson CM, Leonard N, Blakley PM, Nettel-Aguirre A, Sauve RS, Ross DB, Rebeyka IM. Two-year general and neurodevelopmental outcome after neonatal complex cardiac surgery in patients with deletion 22q11.2: a comparative study. J Thorac Cardiovasc Surg. 2007;134:772-9.

Bearden CE, Woodin MF, Wang PP, Moss E, McDonaldMcGinn D, Zackai E, Emannuel B, Cannon TD. The neurocognitive phenotype of the 22q11.2 deletion syndrome: selective deficit in visual-spatial memory. J Clin Exp Neuropsychol. 2001;23:447-64.

Bearden CE, van Erp TG, Dutton RA, Tran H, Zimmermann L, Sun D, Geaga JA, Simon TJ, Glahn DC, Cannon TD, 
Emanuel BS, Toga AW, Thompson PM. Mapping cortical thickness in children with 22q11.2 deletions. Cereb Cortex. 2007;17:1889-98.

Bellinger DC. Cardiac surgery and the brain: differences between adult and paediatric studies. Heart 2003;89:365-6

Bellinger DC, Jonas RA, Rappaport LA, Wypij D, Wernovsky G, Kuban KC, Barnes PD, Holmes GL, Hickey PR, Strand RD. Developmental and neurologic status of children after heart surgery with hypothermic circulatory arrest or low-flow cardiopulmonary bypass. N Engl J Med. 1995;332: 549-55.

Bellinger DC, Wypij D, Kuban KC, Rappaport LA, Hickey PR, Wernovsky G, Jonas RA, Newburger JW. Developmental and neurological status of children at 4 years of age after heart surgery with hypothermic circulatory arrest or lowflow cardiopulmonary bypass. Circulation 1999;100:526-32.

Bingham PM, Zimmerman RA, McDonald-McGinn D, Driscoll D, Emanuel BS, Zackai E. Enlarged Sylvian fissures in infants with interstitial deletion of chromosome 22q11. Am J Med Genet. 1997;74:538-43.

Bish JP, Nguyen V, Ding L, Ferrante S, Simon TJ. Thalamic reductions in children with chromosome 22q11.2 deletion syndrome. Neuroreport 2004;15:1413-5.

Bish JP, Pendyal A, Ding L, Ferrante H, Nguyen V, McDonaldMcGinn D, Zackai E, Simon TJ. Specific cerebellar reductions in children with chromosome 22q11.2 deletion syndrome. Neurosci Lett. 2006;399:245-8.

Bremner JD, Randall P, Scott TM, Bronen RA, Seibyl JP, Southwick SM, Delaney RC, McCarthy G, Charney DS, Innis RB. MRI-based measurement of hippocampal volume in patients with combat-related posttraumatic stress disorder. Am J Psychiatry. 1995;152:973-81.

Campbell LE, Daly E, Toal F, Stevens A, Azuma R, Catani M, $\mathrm{Ng} \mathrm{V}$, van Amelsvoort T, Chitnis X, Cutter W, Murphy DG, Murphy KC. Brain and behaviour in children with 22q11.2 deletion syndrome: a volumetric and voxel-based morphometry MRI study. Brain 2006;129:1218-28.

Chao CP, Zaleski CG, Patton AC. Neonatal hypoxic-ischemic encephalopathy: multimodality imaging findings. Radiographics 2006;26 Suppl 1:S159-72.

Chow EW, Mikulis DJ, Zipursky RB, Scutt LE, Weksberg R, Bassett AS. Qualitative MRI findings in adults with 22q11 deletion syndrome and schizophrenia. Biol Psychiatry. 1999;46:1436-42.

Dale AM, Fischl B, Sereno MI. Cortical surface-based analysis. I. Segmentation and surface reconstruction. Neuroimage 1999;9:179-94.

De Smedt B, Devriendt K, Fryns JP, Vogels A, Gewillig M, Swillen A. Intellectual abilities in a large sample of children with Velo-cardio-facial syndrome: an update. J Intellect Disabil Res. 2007;51:666-70.

Debbané M, Schaer M, Farhoumand R, Glaser B, Eliez S. Hippocampal volume reduction in 22q11.2 deletion syndrome. Neuropsychologia 2006;44:2360-5.

Deboer T, Wu Z, Lee A, Simon TJ. Hippocampal volume reduction in children with chromosome 22q11.2 deletion syndrome is associated with cognitive impairment. Behav Brain Funct. 2007;3:54.

Derogatis L. SCL-90-R administration, scoring and interpretation manual-II. Towson: Clinical Psychometric Research; 1983.

Desikan RS, Sgonne F, Fischl B, Quinn BT, Dickerson BC, Blacker D, Buckner RL, Dale AM, Maguire RP, Hyman BT, Albert MS, Killiany RJ. An automated labeling system for subdividing the human cerebral cortex on MRI scans into gyral based regions of interest. Neuroimage 2006;31:968-80.
Di Paola M, Caltagirone C, Fadda L, Sabatini U, Serra L, Carlesimo GA. Hippocampal atrophy is the critical brain change in patients with hypoxic amnesia. Hippocampus 2008;18:719-28.

Donofrio MT, Bremer YA, Schieken RM, Gennings C, Morton LD, Eidem BW, Cetta F, Falkensammer CB, Huhta JC, Kleinman CS. Autoregulation of cerebral blood flow in fetuses with congenital heart disease: the brain sparing effect. Pediatr Cardiol. 2003;24:436-43.

Eliez S, Schmitt JE, White CD, Reiss AL. Children and adolescents with velocardiofacial syndrome: a volumetric MRI study. Am J Psychiatry. 2000;157:409-15.

Eliez S, Schmitt JE, White CD, Wellis VG, Reiss AL. A quantitative MRI study of posterior fossa development in velocardiofacial syndrome. Biol Psychiatry. 2001;49:540-6.

Eliez S, Barnea-Goraly N, Schmitt JE, Liu Y, Reiss AL. Increased basal ganglia volumes in velo-cardio-facial syndrome (deletion 22q11.2). Biol Psychiatry. 2002;52:68-70.

Fischl B, Dale AM. Measuring the thickness of the human cerebral cortex from magnetic resonance images. Proc Natl Acad Sci USA. 2000;97:11,050-5.

Fischl B, Liu A, Dale AM. Automated manifold surgery: constructing geometrically accurate and topologically correct models of the human cerebral cortex. IEEE Trans Med Imaging. 2001;20:70-80.

Fischl B, Salat DH, Busa E, Albert M, Dieterich M, Haselgrove C, van der Kouwe A, Killiany R, Kennedy D, Klaveness S, Montillo A, Makris N, Rosen B, Dale AM. Whole brain segmentation: automated labeling of neuroanatomical structures in the human brain. Neuron 2002;33:341-55.

Gaynor JW. Periventricular leukomalacia following neonatal and infant cardiac surgery. Semin Thorac Cardiovasc Surg Pediatr Card Surg Annu. 2004;7:133-40.

Gerdes M, Solot C, Wang PP, Moss E, LaRossa D, Randall P, Goldmuntz E, Clark BJ, Driscoll DA, Jawad A, Emanuel BS, McDonald-McGinn DM, Batshaw ML, Zackai EH. Cognitive and behavior profile of preschool children with chromosome 22q11.2 deletion. Am J Med Genet. 1999;85:127-33.

Glaser B, Schaer M, Berney S, Debbane M, Vuilleumier P, Eliez S. Structural changes to the fusiform gyrus: a cerebral marker for social impairments in 22q11.2 deletion syndrome? Schizophr Res. 2007;96:82-6.

Glauser TA, Rorke LB, Weinberg PM, Clancy RR. Congenital brain anomalies associated with the hypoplastic left heart syndrome. Pediatrics 1990;85:984-90.

Gothelf D, Schaer M, Eliez S. Genes, brain development and psychiatric phenotypes in velo-cardio-facial syndrome. Dev Disabil Res Rev. 2008;14:59-68.

Han X, Jovicich J, Salat D, van der Kouwe A, Quinn B, Czanner S, Busa E, Pacheco J, Albert M, Killiany R, Maguire P, Rosas D, Makris N, Dale A, Dickerson B, Fischl B. Reliability of MRI-derived measurements of human cerebral cortical thickness: the effects of field strength, scanner upgrade and manufacturer. Neuroimage 2006;32:180-94.

Hay BN. Deletion 22q11: spectrum of associated disorders. Semin Pediatr Neurol. 2007;14:136-9.

Jourdain P, Nikonenko I, Alberi S, Muller D. Remodeling of hippocampal synaptic networks by a brief anoxiahypoglycemia. J Neurosci. 2002;22:3108-16.

Kates WR, Burnette CP, Jabs EW, Rutberg J, Murphy AM, Grados M, Geraghty M, Kaufmann WE, Pearlson GD. Regional cortical white matter reductions in velocardiofacial syndrome: a volumetric MRI analysis. Biol Psychiatry. 2001;49:677-84.

Kates WR, Burnette CP, Bessette BA, Folley BS, Strunge L, Jabs EW, Pearlson GD. Frontal and caudate alterations in velo- 
cardiofacial syndrome (deletion at chromosome 22q11.2). J Child Neurol. 2004;19:337-42.

Kates WR, Miller AM, Abdulsabur N, Antshel KM, Conchelos J, Fremont W, Roizen N. Temporal lobe anatomy and psychiatric symptoms in velocardiofacial syndrome (22q11.2 deletion syndrome). J Am Acad Child Adolesc Psychiatry. 2006;45:587-95.

Kuperberg GR, Broome MR, McGuire PK, David AS, Eddy M, Ozawa F, Goff D, West WC, Williams SC, van der Kouwe AJ, Salat DH, Dale AM, Fischl B. Regionally localized thinning of the cerebral cortex in schizophrenia. Arch Gen Psychiatry. 2003;60:878-88.

Licht DJ, Wang J, Silvestre DW, Nicolson SC, Montenegro LM, Wernovsky G, Tabbutt S, Durning SM, Shera DM, Gaynor JW, Spray TL, Clancy RR, Zimmerman RA, Detre JA. Preoperative cerebral blood flow is diminished in neonates with severe congenital heart defects. J Thorac Cardiovasc Surg. 2004;128:841-9.

Limperopoulos C, Majnemer A, Shevell MI, Rosenblatt B, Rohlicek C, Tchervenkov C. Neurologic status of newborns with congenital heart defects before open heart surgery. Pediatrics 1999;103:402-8.

Liu AY, Zimmerman RA, Haselgrove JC, Bilaniuk LT, Hunter JV. Diffusion-weighted imaging in the evaluation of watershed hypoxic-ischemic brain injury in pediatric patients. Neuroradiology 2001;43:918-26.

Machado AM, Simon TJ, Nguyen V, McDonald-McGinn DM, Zackai EH, Gee JC. Corpus callosum morphology and ventricular size in chromosome 22q11.2 deletion syndrome. Brain Res. 2007;1131:197-210.

Mahle WT, Tavani F, Zimmerman RA, Nicolson SC, Galli KK, Gaynor JW, Clancy RR, Montenegro LM, Spray TL, Chiavacci RM, Wernovsky G, Kurth CD. An MRI study of neurological injury before and after congenital heart surgery. Circulation 2002;106:I109-14.

Martens MA, Wilson SJ, Reutens DC. Research review: Williams syndrome: a critical review of the cognitive, behavioral, and neuroanatomical phenotype. J Child Psychol Psychiatry. 2008;49:576-608.

McDonald-McGinn DM, Kirschner R, Goldmuntz E, Sullivan K, Eicher P, Gerdes M, Moss E, Solot C, Wang P, Jacobs I, Handler S, Knightly C, Heher K, Wilson M, Ming JE, Grace K, Driscoll D, Pasquariello P, Randall P, Larossa D, Emanuel BS, Zackai EH. The Philadelphia story: the 22q11.2 deletion: report on 250 patients. Genet Couns. 1999; 10:11-24.

McEwen BS. Stress and hippocampal plasticity. Annu Rev Neurosci. 1999;22:105-22.

Meyer-Lindenberg A, Mervis CB, Berman KF. Neural mechanisms in Williams syndrome: a unique window to genetic influences on cognition and behaviour. Nat Rev Neurosci. 2006;7:380-93.

Miller SP, McQuillen PS, Hamrick S, Xu D, Glidden DV, Charlton N, Karl T, Azakie A, Ferriero DM, Barkovich AJ, Vigneron DB. Abnormal brain development in newborns with congenital heart disease. N Engl J Med. 2007;357: 1928-38.

Nelson DP, Andropoulos DB, Fraser CD. Perioperative neuroprotective strategies. Semin Thorac Cardiovasc Surg Pediatr Card Surg Annu. 2008;11:49-56.

Newburger JW, Silbert AR, Buckley LP, Fyler DC. Cognitive function and age at repair of transposition of the great arteries in children. N Engl J Med. 1984;310:1495-9.

Rosas HD, Liu AK, Hersch S, Glessner M, Ferrante RJ, Salat DH, van der Kouwe A, Jenkins BG, Dale AM, Fischl B.
Regional and progressive thinning of the cortical ribbon in Huntington's disease. Neurology 2002;58:695-701.

Ryan AK, Goodship JA, Wilson DI, Philip N, Levy A, Seidel H, Schuffenhauer S, Oechsler H, Belohradsky B, Prieur M, Aurias A, Raymond FL, Clayton-Smith J, Hatchwell E, McKeown C, Beemer FA, Dallapiccola B, Novelli G, Hurst JA, Ignatius J, Green AJ, Winter RM, Brueton L, BrndumNielsen K, Scambler PJ. Spectrum of clinical features associated with interstitial chromosome 22q11 deletions: a European collaborative study. J Med Genet. 1997;34: 798-804.

Salat DH, Buckner RL, Snyder AZ, Greve DN, Desikan RS, Busa E, Morris JC, Dale AM, Fischl B. Thinning of the cerebral cortex in aging. Cereb Cortex. 2004;14:721-30.

Sapolsky RM. Glucocorticoids and hippocampal atrophy in neuropsychiatric disorders. Arch Gen Psychiatry. 2000;57: 925-35.

Scambler PJ. The 22q11 deletion syndromes. Hum Mol Genet. 2000;9:2421-6.

Schaer M, Eliez S. From genes to brain: understanding brain development in neurogenetic disorders using neuroimaging techniques. Child Adolesc Psychiatr Clin N Am. 2007; 16:557-79.

Schaer M, Glaser B, Cuadra MB, Debbane M, Thiran JP, Eliez S. Congenital heart disease affects local gyrification in 22q11.2 deletion syndrome. Dev Med Child Neurol. 2009;51: $746-53$.

Sgonne F, Dale AM, Busa E, Glessner M, Salat D, Hahn HK, Fischl B. A hybrid approach to the skull stripping problem in MRI. Neuroimage 2004;22:1060-75.

Shillingford AJ, Glanzman MM, Ittenbach RF, Clancy RR, Gaynor JW, Wernovsky G. Inattention, hyperactivity, and school performance in a population of school-age children with complex congenital heart disease. Pediatrics 2008;121:e759-67.

Shprintzen RJ. Velo-cardio-facial syndrome: a distinctive behavioral phenotype. Ment Retard Dev Disabil Res Rev. 2000;6:142-7.

Simon T, Bearden CE, Moss E, McDonald-McGinn D, Zackai E, Wang P. Cognitive development in VCFS. Progress in Pediatric Cardiology. 2002;15:109-17.

Simon TJ, Ding L, Bish JP, McDonald-McGinn DM, Zackai EH, Gee J. Volumetric, connective, and morphologic changes in the brains of children with chromosome 22q11.2 deletion syndrome: an integrative study. Neuroimage 2005;25: 169-80.

Swillen A, Devriendt K, Legius E, Eyskens B, Dumoulin M, Gewillig M, Fryns JP. Intelligence and psychosocial adjustment in velocardiofacial syndrome: a study of 37 children and adolescents with VCFS. J Med Genet. 1997;34:453-8.

Swillen A, Devriendt K, Legius E, Prinzie P, Vogels A, Ghesquire P, Fryns JP. The behavioural phenotype in velocardio-facial syndrome (VCFS): from infancy to adolescence. Genet Couns. 1999;10:79-88.

Teipel SJ, Hampel H. Neuroanatomy of Down syndrome in vivo: a model of preclinical Alzheimer's disease. Behav Genet. 2006;36:405-15.

Wernovsky G, Shillingford AJ, Gaynor JW. Central nervous system outcomes in children with complex congenital heart disease. Curr Opin Cardiol. 2005;20:94-9.

Wray J. Intellectual development of infants, children and adolescents with congenital heart disease. Dev Sci. 2006;9: 368-78.

van der Zwan A, Hillen B. Review of the variability of the territories of the major cerebral arteries. Stroke 1991;22:1078-84. 